\title{
Medical knowledge on ionizing radiations
}

Dear Editor,

I have read with great concern the article written by Borém et al. (1) - "The knowledge about diagnostic imaging methods among primary care and medical emergency physicians" -, published by Radiologia Brasileira in December/2013.

The presented results show in a hard-hitting way that physicians are educated even without an appropriate idea about what is ionizing radiation, radiological imaging and inherent risks. I herein transcribe the following sentence: "A significant proportion of the studied professionals consider that radiography ( $n=53 ; 65 \%)$ and computed tomography (CT) ( $n=41 ; 51 \%)$ do not utilize ionizing radiation, while $43 \%(n=35)$ and $42 \%(n=34)$ consider that ultrasonography (US) and magnetic resonance imaging (MRI) do utilize ionizing radiation."

The authors have observed that $56 \%$ of the respondents did not have a satisfactory knowledge about the correct indication for the study in common clinical situations. This is clearly a failure of the system and of physicians' education, since it is essential that physicians have a clear understanding about the indications of radiological examinations. In large cities, sophisticated, sometimes unnecessary imaging studies are frequently requested because the assisting physician does not have in mind that the radiation dose delivered by a chest CT scan corresponds to the dose delivered by approximately 200 to 500 chest radiographies ${ }^{(2)}$, not to mention the much higher cost of computed tomography. In more sophisticated hospitals, there is the so called flu kit: a child with fever and flu signs is submitted to chest and face sinuses radiography; in case of normal results, the child is submitted to chest and facial sinuses CT.

Considering the experience acquired over more than twenty years teaching Radiology, I think that it is necessary to rethink the curricular reforms, the modern pedagogy, distance teaching and learning, the internet, the tablets, and seriously thinking of resuming the education of physicians enabling them to care for human beings.

There was a time when Radiology was a mandatory basic discipline. Nowadays, there is even who thinks that it is possible to educate physicians through the internet or by means of PowerPoint ${ }^{\circledR}$ presentations. "Facilities" are increasingly created, thus it is becoming more and more difficult to understand the actual objective of such maneuvers. However, after finding misspelled words ["equiterico" instead of "ictérico" (icteric); "resperação alfegante" instead of "respiração ofegante" (wheezing breath), or "crosta da aorta calcificada" instead of "croça aórtica calcificada" (calcified aortic arch)] on written exams of graduate students, we start believing that anything can facilitate the obtention of a diploma. I think that those involved in the education of such physicians should be mandatorily cared by one of their students.

A simple and quick glance at the files of Radiologia Brasileira/ 2013 shows plenty of articles enough to teach anyone interested in learning about radiations and inherent risks ${ }^{(3-7)}$. But for this the physicians must be willing to learn. Regrettably, we have noticed with concern that they are not interested.

Antonio Carlos Pires Carvalho

Associate Professor, PhD, Department of Radiology - School of Medicine, Adjunct Coordinator for the Program of Post-graduation in Medicine (Radiology) Universidade Federal do Rio de Janeiro (UFRJ), Rio de Janeiro, RJ, Brazil. E-mail: acpcrj@hucff.ufrj.br.

\section{References}

1. Borém LMA, Figueiredo MFS, Silveira MF, et al. O conhecimento dos médicos da atenção primária à saúde e da urgência sobre os exames de imagem. Radiol Bras. 2013;46:341-5.

2. Brown $\mathrm{N}$, Jones $\mathrm{L}$. Knowledge of medical imaging radiation dose and risk among doctors. J Med Imaging Radiat Oncol. 2013;57:8-14.

3. Terini RA, Campelo MCS, Almeida Jr JN, et al. Monitoração de doses em radiologia: a calibração de medidores do produto kerma-área (PKA). Radiol Bras. 2013;46:358-66.

4. Oliveira CM, Sá LV, Alonso TC, et al. Sugestão de nível de referência em diagnóstico nacional para ${ }^{18} \mathrm{~F}-\mathrm{FDG} / \mathrm{PET}$ em procedimentos oncológicos adultos no Brasil. Radiol Bras. 2013;46:284-9.

5. Parente DB. Radiation risk in the indiscriminate use of CT scan. Radiol Bras. 2013;46(2):v-vi.

6. Costa DMC, Salvadori PS, Monjardim RF, et al. When the non-contrast-enhanced phase is unnecessary in abdominal computed tomography scans? A retrospective analysis of 244 cases. Radiol Bras. 2013;46:197-202.

7. Salvadori PS, Costa DMC, Romano RFT, et al. What is the real role of the equilibrium phase in abdominal computed tomography? Radiol Bras. 2013; $46: 65-70$. 